\title{
Ectopic pregnancy and unsupervised abortion pills: the hidden truth
}

\author{
Neha Singh, Kushla Pathania*, Kalpna Negi, Sanjay Rathod
}

Department of Obstetrics and Gynaecology, Kamla Nehru Hospital, IGMC Shimla, Himachal Pradesh, India

Received: 28 December 2021

Accepted: 11 January 2022

\author{
*Correspondence: \\ Dr. Kushla Pathania, \\ E-mail: dr.kushla@gmail.com
}

Copyright: () the author(s), publisher and licensee Medip Academy. This is an open-access article distributed under the terms of the Creative Commons Attribution Non-Commercial License, which permits unrestricted non-commercial use, distribution, and reproduction in any medium, provided the original work is properly cited.

\begin{abstract}
Background: Aim of the study was the indiscriminate use of self-consumption of abortion pills and its association with complication like ectopic pregnancy reporting to a tertiary care center.

Methods: The study was a prospective observational study conducted in the department of obstetrics and gynecology, Kamla Nehru State hospital for mother and child, Indira Gandhi medical college Shimla w.e.f. $1^{\text {st }}$ July 2018 to $30^{\text {th }}$ June 2019. A total of 27 women reported to the hospital who were diagnosed of having ectopic pregnancy after intake of abortion pills.

Results: A total of 27 cases presented to the hospital who were diagnosed to have ectopic pregnancy. Maximum 18 $(67 \%)$ cases were in 21-30 years of age group. Married women constituted 21 (77\%) cases. The $14(52 \%)$ belonged to rural area while $13(48 \%)$ belonged to urban area. The chemist was found to be source of procurement in 19 (70\%) cases, private practitioner in $6(22 \%)$ cases and only two consumed pills after consultation with registered doctor.

Conclusions: This study shows urgent need for legislation and restriction of drugs used for medical termination of pregnancy. Drugs should be made available via health care facilities under supervision to reduce maternal mortality and morbidity due to indiscriminate use of these pills.
\end{abstract}

Keywords: Over the counter. MTP pills, Incomplete abortion, Rupture uterus, Ectopic pregnancy

\section{INTRODUCTION}

Abortion has been practiced over ancient times by means of various methods. Laws, cultural and religious views related to abortion are different all around the world and have evolved over various eras. Abortion is a willful termination of pregnancy beyond period of viability. ${ }^{1}$ Medical abortion is defined by World health organization as "Usage of pharmacological drugs to terminate pregnancy. ${ }^{2}$ World health organization defines unsafe abortion as a procedure for terminating an unwanted pregnancy either by persons lacking the necessary skills or in environment lacking minimal medical standards or both. Abortion has been legal in India for over four decades since the introduction of medical termination of pregnancy act 1971. The goal of act was to regulate and ensure access to safe abortion. ${ }^{4}$ And thus protect women from "Inflicted pregnancies" and "Forced motherhood". It was amended in years 2003 and medical method of abortion using mifepristone and misoprostol was approved as legal method for termination of early pregnancy. ${ }^{5}$ As per world health organization and federation of obstetrics and gynecological society of India guidelines for medical termination of pregnancy by medical method includes proper counseling of women, confirmation of pregnancy, estimation of correct gestational age and site by bimanual examination, ruling out contraindication, and follow up visit on $14^{\text {th }}$ day are considered mandatory. Ultrasound examination is an optional modality. ${ }^{6}$ The term "selfmedication" is applied when patient, her husband, her relative or her friend has brought the abortion pill (for patient) over the counter without medical guidance/ supervision/ prescription. ${ }^{7}$ The most common providers are traditional birth attendants, nurses, midwifes, pharmacists or quacks. ${ }^{8}$ With self-administration of abortion pills Where site of pregnancy is not confirmed 
before pill consumption sometimes life threatening conditions like ectopic pregnancy can be missed and may endanger life of a women and already anemic females can become more so by irrational use of these pills. ${ }^{9}$ Ectopic pregnancy is a leading cause of maternal mortality and morbidity in the first trimester. The incidence of ectopic pregnancy has risen and accounts for $2 \%$ of all pregnancy. High index of suspicion and use of Transvaginal Ultrasound with assay of beta HCG can help in timely diagnosis of ectopic pregnancy. ${ }^{10}$

\section{METHODS}

\section{Study design}

The study type was of prospective observational study.

It was conducted in the department of obstetrics and gynecology, Kamla Nehru State hospital for mother and child, Indira Gandhi medical college Shimla w.e.f. $1^{\text {st }}$ July 2018 to $30^{\text {th }}$ June 2019.

A total of 27 women reported to the hospital who were diagnosed of having ectopic pregnancy after intake of abortion pills.

On admission any signs and symptoms of shock was ruled out and if present was managed as per protocol. After stabilizing the patient or if patient is already stable data was collected as per the Proforma. Gestation at which pill was taken, whether pelvic examination or ultrasound was done prior to it or not, who prescribed the drug and from where it was procured was noted.

\section{Data analysis}

Data collected was transformed into MS excel sheet for further processing and analysis. appropriate spastically software and tools were used for analyzing data. parametric and non-parametric test of significance were used accordingly to find the association between quantitative and qualitative variables of interest. results were summarized in tables. The names of patient kept confidential.

\section{RESULTS}

A total of 27 cases presented to the hospital who were diagnosed to have ectopic pregnancy. Out of these 27 cases, 25 cases had history of intake of unsupervised abortion pills and only 2 cases presented with history of intake of supervised abortion pills from licensed sources.

Table 1: Age distribution $(\mathrm{n}=25)$.

\begin{tabular}{|lll|}
\hline Age (Years) & Number & Percentage (\%) \\
\hline $\mathbf{2 0}$ & 7 & 26 \\
\hline $\mathbf{2 1 - 3 0}$ & 18 & 67 \\
\hline $\mathbf{3 1 - 3 5}$ & 2 & 7.4 \\
\hline $\mathbf{3 5}$ & 1 & 3.7 \\
\hline
\end{tabular}

Maximum $18(67 \%)$ cases were in 21-30 years of age group. Seven $(26 \%)$ were below or equal to 20 years of age. Two $(7.4 \%)$ cases were in the age group of $31-35$ years and only $1(3.7 \%)$ case was above 35 years. Married women constituted $21(77 \%)$ cases and $6(22 \%)$ cases were unmarried which points out its more usage for spacing pregnancy. Maximum i.e., 14 (52\%) belonged to rural area while $13(48 \%)$ belonged to urban area. Majority cases had gravidity 2 i.e., $11(41 \%)$ cases, only $2(7 \%)$ cases were primigravida.

Table 2: Source of procurement of abortion pills.

\begin{tabular}{|lll|}
\hline Source & Number & Percentage (\%) \\
\hline Chemist & 19 & 70 \\
\hline Private practitioner & 6 & 22 \\
\hline Doctor (Registered) & 2 & 7 \\
\hline
\end{tabular}

The chemist was found to be source of procurement in 19 $(70 \%)$ cases, private practitioner in $6(22 \%)$ cases and only two consumed pills after consultation with registered doctor.

Table 3: Ultrasound findings.

\begin{tabular}{|lll|}
\hline Ultrasound finding & Number & Percentage (\%) \\
\hline Ruptured ectopic & 16 & 59 \\
\hline Unruptured ectopic & 9 & 33 \\
\hline $\begin{array}{l}\text { Abdominal } \\
\text { pregnancy }\end{array}$ & 1 & 4 \\
\hline Hemorrhagic cyst & 1 & 4 \\
\hline
\end{tabular}

On admission ultrasound showed ruptured ectopic in 18 cases and 9 cases had unruptured ectopic pregnancy.

Table 4: Management.

\begin{tabular}{|lll|}
\hline $\begin{array}{l}\text { Management } \\
\text { Exploratory } \\
\text { laparotomy proceed } \\
\text { salpingectomy }\end{array}$ & 16 & 59 \\
\hline $\begin{array}{l}\text { Exploratory } \\
\text { laparotomy proceeds } \\
\text { excision of secondary } \\
\text { abdominal pregnancy }\end{array}$ & 6 & 22 \\
\hline $\begin{array}{l}\text { Exploratory } \\
\text { laparotomy proceed } \\
\text { cystectomy }\end{array}$ & 1 & 4 \\
\hline Methotrexate & 1 & 4 \\
\hline
\end{tabular}

Out of these $18(70 \%)$ cases of ruptured ectopic $16(59 \%)$ cases underwent exploratory laparotomy for ruptured ectopic, $1(3.7 \%)$ case was found out to be ruptured hemorrhagic cyst and underwent cystectomy, while 1 $(3.7 \%)$ case was found to have secondary abdominal pregnancy located in the omentum and underwent exploratory laparotomy proceed excision of secondary abdominal pregnancy. Unruptured ectopic was seen in 9 $(33 \%)$ cases out of which $6(22 \%)$ cases were given 
methotrexate while other $3(11 \%)$ cases were kept on expectant management.

\section{DISCUSSION}

In the present study maximum intake of pills was seen in age group of 21 to 30 years i.e., 18 (67\%) cases, showing that the young age groups were more likely to be influenced by inadvertent advertisements leading to pill consumption. It was comparable to study done by Munshi et al, Sarojini et al and Bajwa et al (Table 5). ${ }^{1,3,12}$

Table 5: Age groups with maximum intake of abortion pills.

\begin{tabular}{|c|c|c|}
\hline Study & $\begin{array}{l}\text { Age group } \\
\text { (Years) }\end{array}$ & $\begin{array}{l}\text { Percentage } \\
(\%)\end{array}$ \\
\hline Bajwa et al, $(2011)^{12}$ & $20-30$ & 59.62 \\
\hline Sarojini et al, $(2017)^{3}$ & $20-30$ & 59.6 \\
\hline Munshi et al, (2018) ${ }^{1}$ & $20-30$ & 75 \\
\hline Present study & $21-30$ & 67 \\
\hline
\end{tabular}

\section{Marital status}

In the present study maximum cases 21 (77\%) were married but were not prepared for a child and were open to resorts like over the counter medical abortifacients for easy solution. It was comparable to other studies conducted by Thaker et al, Agarwal et al and Munshi et al (2018). This shows that abortion pills rather than being used for indicated indications that are given under MTP act is being used as a substitute for contraception by the age group of high fertility and reproductive potential. This can lead to deleterious effects on health of females and also on health facilities. This also reflects the lack of contraception counselling and its usage..$^{7,1,2}$

Table 6: Marital status of cases.

\begin{tabular}{|c|c|}
\hline Study & Married \\
\hline Thaker et al, $(2014)^{7}$ & 94.5 \\
\hline Agarwal et al, $(2016)^{2}$ & 100 \\
\hline Munshi et al, (2018) ${ }^{1}$ & 100 \\
\hline Present study & 77 \\
\hline
\end{tabular}

\section{Source of procurement}

In the present study it was found that in $19(79 \%)$ cases the person recommending the medication was pharmacists. The results were similar to the studies done by Thaker et al and Agarwal et al. Under MTP amendment act, pharmacist are only supposed to sell medical abortifacient by prescription, but it doesn't happen. The relative anonymity, easy accessibility, hasty transactions and saving cost makes pharmacists the first choice for getting abortion pills. As they serve as first contact for female seeking abortion pills strict legislation against them can prove helpful in reducing unsafe abortions (Table 7). ${ }^{7,2}$
Table 7: Source of procurement of abortion pills.

\begin{tabular}{|c|c|c|}
\hline Study & $\begin{array}{l}\text { Prescribed } \\
\text { by }\end{array}$ & $\begin{array}{l}\text { Percentage } \\
(\%)\end{array}$ \\
\hline Thaker et al, (2014) ${ }^{7}$ & Pharmacist & 70.2 \\
\hline Agarwal et al, $(2016)^{2}$ & Pharmacist & 73.33 \\
\hline Present study & Pharmacist & 79.3 \\
\hline
\end{tabular}

\section{Ectopic pregnancy}

In the present study ectopic pregnancy was diagnosed in 25 cases, out of which $15(12.3 \%)$ cases were ruptured, 9 $(7.4 \%)$ cases were unruptured and $1(0.8 \%)$ case had secondary abdominal pregnancy. Laparotomy was performed in all $15(12.3 \%)$ cases of ruptured ectopic and $1(0.8 \%)$ case of secondary abdominal ectopic pregnancy whereas only $6(4.9 \%)$ cases of unruptured required medical management and $3(2.4 \%)$ cases were managed expectantly. Incidence was found to be lower in study conducted by Thaker et al, Giri et al and Bhalla et al. As these women were not counselled properly regarding the possibility of extra uterine pregnancy and bimanual examination/ USG was also not done to confirm uterine size, gestational age and site of pregnancy, ectopic pregnancy went undetected (Table 8). ${ }^{7,13,14}$

Table 8: Ectopic pregnancy in unsupervised abortion pills.

\begin{tabular}{|c|c|}
\hline Study & Ectopic pregnancy (\%) \\
\hline Thaker et al, $(2014)^{7}$ & 5.4 \\
\hline Giri et al, $(2015)^{13}$ & 6.25 \\
\hline Bhalla et al, $(2018)^{14}$ & 5 \\
\hline
\end{tabular}

\section{Limitations}

Limitation of the study include that sample size of the study was could have been more by including all the other colleges of the state. Many patients hide the history of intake of abortion pills due to stigma attached to it that can lead to faulty data.

\section{CONCLUSION}

The choice to embrace motherhood or not has been solely provided by government of India to the mother to be. The freedom of choosing termination till required period of gestation and without consent of any other person involved is one of the most liberating reproductive rights which has been provided to all women by the society. It helps to save them from mental, social and economic trauma. As we all know all freedoms and rights comes with an unsaid responsibility which we all as a citizen should understand and follow. The use of this freedom without consultation of a licensed service provider turns this boon into Bain. The rate of ectopic pregnancy has increased over the years which can be attributed to advancing age of conception and more detection by better resolution ultrasound machines and higher sensitivity testing. The clear guidelines on prescription of pills after bimanual examination or an 
ultrasound examination were the only prerequisites before pill intake which when not followed leads to development of preventable co morbidities like anemia, shock and even death. Thus, a combined approach of educating female, strict legislation against pharmacists, warning labels on combi packs, proper reporting of People providing unsupervised pills over the counter can help us as a society to safeguard our females, as a healthier female is directly equal to a better tomorrow.

Funding: No funding sources Conflict of interest: None declared

Ethical approval: The study was approved by the Institutional Ethics Committee

\section{REFERENCES}

1. Munshi KS, Thaker RV, Shah JM, Mewada BN. Selfmedication of abortion pills and its complication: an observational study. Int J Reprod Contracept Obstet Gynecol. 2018;7:205-9.

2. Agarwal M, Datta A. How safe are over the counter abortion pills-differences between its intended and practical usage and its implications- a study conducted in a tertiary care centre in Shillong, Meghalaya, India. Int J Reprod Contracept Obstet Gynecol. 2016;5:3036-4.

3. Sarojini, Ashakiran TR, Bhanu BT, Radhika. Over the counter MTP pills and its impact on Women's Health. J Obstet Gynecol India. 2017;67(1):37-41.

4. Government of India. The Medical Termination of pregnancy act, no.34;1971. Available at: http://tcw.nic.in/acts/MTP-act-1971. Pdf Assessed on 26 June 2018.

5. Government of India. The medical Termination of pregnancy Rules (Amendment); 2002. Available at: https://mohfw.gov.in/acts-rules-and-standardshealth.../acts/MTP-act-amendment-2002. Assessed on 26 June 2018.

6. WHO. Fact sheet: Safe abortion: technical and policy guidance for health systems, second edition, 2012 available at: http://www.who.int/reproductivehealth/publications/ unsafe_abortion/9789241548434/en/. Accessed on 17 October 2018.

7. Thaker RV, Deliwala KJ, Shah PT. Self-Medication of Abortion Pill: Women's Health in Jeopardy. NHL J Med Sci. 2014;3(1):26-31.

8. Mishra A, Yadav A, Malik S, Purwar R, Kumari S. Over the counter sale of drugs for medical abortionknowledge, attitude and Practices of pharmacists of Delhi, India. Int J Pharma Res. 2016;6(3):92-6.

9. Verma S, Ranjan R, Batra M. Case control study of supervised and unsupervised medical abortion in first trimester of pregnancy. Int $\mathrm{J}$ Reprod Contracept Obstet Gynecol. 2016;5(7):2367-71.

10. Debnath J, Gulati SK, Mathur A, Gupta R, Kumar N, Arora S. Ectopic pregnancy in the Era of Medical Abortion: Are We Ready for it? Spectrum of Sonographic Findings and Our Experience in a Tertiary Care Service Hospital of India. J Obstet Gynecol India. 2013;63(6):388-93.

11. Joshi AP, Chitrakar NS, Pariyar J, Shrestha I, Maharjan R, Maharjan P. Undiagnosed Ectopic Pregnancy among Unsupervised use of Medical Abortion pills. Nepal J Obstet Gynecol. 2016;22(2):12-5.

12. Bajwa SK, Bajwa SJS, Ghai GK, Singh N, Singh A, Goraya SPS. Medical abortion: Is it a blessing or curse for the developing nations? Srilanka J Obstet Gynecol. 2011;33(3):84-90.

13. Giri A, Srivastav VR, Suwal A, Sharma B. A study of Complications following self-administration with Medical Abortion Pills. Nepal J Obstet Gynecol. 2015;19(1):20-4.

14. Bhalla S, Goyal LD, Bhalla S, Kaur B. Selfadministered medical abortion pills: evaluation of the clinical outcome and complications among women presenting with unsupervised pill intake to a tertiary care hospital in Malwa region of Punjab, India. Int $\mathbf{J}$ Reprod Contracept Obstet Gynecol. 2018;7(4):153742.

Cite this article as: Singh N, Pathania K, Negi K, Rathod S. Ectopic pregnancy and unsupervised abortion pills: the hidden truth. Int J Reprod Contracept Obstet Gynecol 2022;11:469-72. 